\title{
Ureteral Stricture
}

National Cancer Institute

\section{Source}

National Cancer Institute. Ureteral Stricture. NCI Thesaurus. Code C78661.

Narrowing of the lumen of the ureter. 